\title{
A construção do direito ao duplo grau de jurisdição nas cortes europeia e interamericana de direitos humanos
}

\author{
The construction of the law of jurisdiction in the european and inter-american \\ court of human rights
}

\author{
Andrea de Quadros Dantas Echeverria* \\ Marcelo Dias Varella ${ }^{* *}$
}

\section{Resumo}

\begin{abstract}
A divergência do modelo de direito ao duplo grau de jurisdição construído no âmbito das Cortes suscitou o questionamento acerca da resistência da Corte Interamericana em aplicar a margem de apreciação nacional, culminando na observância de que o histórico de ditaduras militares e a atual instabilidade política dos Estados latino-americanos geram uma certa desconfiança da Corte Interamericana, que impede uma delegação de competência para o âmbito doméstico. Assim, enquanto a Corte Europeia promove uma internacionalização do direito em parceria com os Estados, tendo por fundamento um pluralismo ordenado, a Corte Interamericana estabelece uma centralização do processo de internacionalização, atribuindo-Ihe a competência para exercer um controle abstrato das normas mediante o controle de convencionalidade. Resta questionar se haveria espaço para o pluralismo no processo de harmonização do direito, como proposto pela Corte Interamericana, ou se se estaria diante de uma simples unificação forçada.
\end{abstract}

Palavras-chave: Duplo grau de jurisdição. Corte Europeia de Direitos Humanos. Corte Interamericana de Direitos Humanos. Pluralismo ordenado. Controle de convencionalidade.

\section{Abstract}

The divergence of the model of law to the double degree of jurisdiction built within the Courts has raised the question of the resistance of the Inter-American Court to apply the national margin of appreciation, culminating in the observance that the history of military dictatorships and the current political instability of the Latin American states generate a certain distrust of the Inter-American Court, which prevents a delegation of competence to the domestic sphere. Thus, while the European Court promotes an internationalization of law in partnership with States, on the basis of orderly pluralism, the Inter-American Court establishes a centralization of the internationalization process, assigning it the competence to exercise an abstract control of the norms through the control of conventionality. It remains to question whether there would be room for pluralism in the process of harmonization of law, as proposed by the Inter-American Court, or whether it would be faced with a simple forced unification.

Keywords: Double degree of jurisdiction. European Court of Human Rights. Inter-American Court of Human Rights. Orderly pluralism. Conventionality control.

\section{Introdução}

As garantias procedimentais são primordiais para que seja possível a proteção de todos os demais direitos, razão pela qual sua proteção se reveste de igual importância, estando previstas tanto na Conveção

Doutoranda pelo Centro Universitário de Brasília/UniCeub. Pesquisadora Visitante em Stanford University, Estado da California-CA/USA. Mestre pelo Centro Universitário de Brasília/UniCeub. Advogada da União. Brasília - DF- Brasil. E-mail: andreaqdantas@gmail.com.

Doutor em Direito pela Universidade de Paris, Panthéon-Sorbonne (2002). Livre-docente em Direito Internacional pela Faculdade de Direito da Universidade de São Paulo (2013). Pós-Doutorado em Direito nas Universidades da California, em Berkeley; George Washington; e Georgetown (2011 e 2012). Professor do Programa de Mestrado e Doutorado em Direito do Centro Universitário de Brasília. Bolsista de Produtividade em Pesquisa nível I do CNPq. Brasília-DF-Brasil. E-mail: marcelodvarella@gmail.com. 
europeia como na americana de direitos humanos. Entre essas, o direito ao devido processo legal objetiva essencialmente garantir o próprio direito de acesso à justiça, na medida em que assegura que o pedido formulado será analisado dentro de um procedimento previamente estabelecido que observe, dentre outros, os princípios do contraditório, da ampla defesa e do duplo grau de jurisdição.

O ponto é particularmente relevante no Brasil pela sistemática de apreciação do Supremo Tribunal Federal em casos recentes, como os casos de corrupção envolvendo diversos agentes políticos com foro privilegiado. A preservação dos princípios da ampla defesa, do juiz natural e do duplo grau de jurisdição é essencial para a preservação dos julgamentos. O conhecimento dos problemas suscitados nos diferentes países pode contribuir para melhor delinear os contornos do princípio do duplo grau de jurisdição no judiciário brasileiro.

Considerando os limites e o escopo do presente artigo, será analisado tão somente um dos aspectos das garantias judiciais de ampla defesa, qual seja, o direito ao duplo grau de jurisdição, a partir da leitura das decisões dos tribunais regionais dos direitos humanos. Busca-se mostrar que cada tribunal adotou estratégia própria para consolidar diferentes direitos relacionados ao princípio. No caso da Corte Europeia de Direitos Humanos (CEDH), privilegiou-se a margem nacional de apreciação. No caso da Corte Interamericana de Direitos Humanos (CIDH), o oposto.

Para demonstrar a ideia, o artigo é dividido em duas partes. Na primeira, discutem-se as decisões da CEDH e CIDH em diferentes casos que construíram a jurisprudência recente em torno do tema. Na segunda parte, discutem-se como essas decisões podem ser interpretadas à luz das diferentes estratégias dos tribunais para a construção regional dos direitos humanos.

\section{0 duplo grau de jurisdição na Corte Europeia de Direitos Humanos}

Apesar da ausência de garantia expressa na Convenção Europeia, a jurisprudência da CEDH já indicava a importância em proteger o processual princípio da ampla defesa, ao afirmar que, embora a Convenção não obrigue os Estados contratantes a estabelecerem tribunais de apelação ou de cassação, os Estados que instituam tais órgãos devem assegurar a observância dos direitos fundamentais previstos no artigo $6^{\circ}$ da Convenção.

Ao contrário da Convenção Americana de Direitos Humanos, a Convenção Européia - em seu texto original - não apresenta o duplo grau de jurisdição como uma garantia expressa, tendo tal direito sido incluído, posteriormente, mediante $o$ artigo $2^{\circ}$ do Protocolo $n^{\circ} 7$, que assim dispõe:

Artigo $2^{\circ}$ - Direito a um duplo grau de jurisdição em matéria penal

2. Este direito pode ser objeto de exceções em relação a infracções menores, definidas nos termos da lei, ou quando o interessado tenha sido julgado em primeira instância pela mais alta jurisdição ou declarado culpado e condenado no seguimento de recurso contra a sua absolvição.

Percebe-se que o dispositivo que garante o duplo grau de jurisdição criminal no âmbito europeu é bastante claro ao estabelecer três principais exceções a essa garantia, sendo, portanto, dispensada a previsão de recurso: (1) quando se tratar de infração de menor potencial ofensivo; (2) quando o indivíduo tenha sido julgado pelo tribunal de maior hierarquia ou tenha sido condenado após recurso contra decisão absolutória; e (3) quando o interessado for julgado pelo tribunal de maior hierarquia de seu país.

Exatamente em razão da clareza da redação do dispositivo, há poucos julgados da Corte Européia questionando o alcance dessa garantia. Também é possível observar que os precedentes da CEDH proporcionam maior segurança jurídica, na medida em que apenas confirmam o que já expresso no citado dispositivo. A aplicação do princípio foi apreciada pela CEDH em algumas ocasiões, notadamente no que se refere a nuances dos pontos acima, como o conceito de infração menor ou a obrigatoriedade dos tribunais superiores revisarem apenas parcialmente as decisões de primeira instância. 
No tocante ao conceito de 'infrações menores', o Estado tem margem de apreciação para definir o que entende do conceito e, assim, restringir o direito ao do cidadão ao duplo grau de jurisdição. Busca-se garantir celeridade processual, o que vem inclusive em defesa do próprio interessado, desde que sem ameaçar o direito à liberdade. De forma geral, a gravidade do crime é associada à pena de prisão. Embora a exposição de motivos do Protocolo 7 esclareça que um importante critério a ser considerado na definição de uma infração como "menor" seja a imputação da penalidade de prisão, a questão foi algumas vezes submetida a CEDH.

No precedente Zaicevs vs. Letônia, a Corte reafirmou que a pena prevista para o crime é o principal critério para esse seja classificado como uma "infração menor", o que possibilitaria o julgamento em apenas uma instância, sem que isso configure violação ao devido processo legal.

Nesse contexto, a CEDH confirmou que a previsão da pena de detenção não permite que tal infração seja classificada como menor, devendo, portanto, ser observado o princípio do duplo grau de jurisdição, consoante se observa do seguinte trecho do julgamento: "55. [...] The Court noted that an offence for which the legislation laid down a custodial sentence as the principal penalty could not be described as 'minor' for the purposes of the second paragraph of that Article. There had been a violation".

Ainda na exposição de motivos, foram reconhecidas as diferenças na amplitude dos recursos disponíveis nos sistemas domésticos para se concluir que a modalidade e a forma para o exercício do direito ao duplo grau de jurisdição deverão ser determinadas pelas leis internas, consoante se observa do seguinte trecho:

18. Different rules govern review by a higher tribunal in the various member States of the Council of Europe. In some countries, such review is in certain cases limited to questions of law, such as the recours en cassation. In others, there is a right to appeal against findings of facts as well as on the questions of law. The article leaves the modalities for the exercise of the right and the grounds on which it may be exercised to be determined by domestic law. (Grifo nosso).

Logo, cada país tem a liberdade de escolher os limites do conceito de penas de menor potencial ofensivo, ou seja, houve delegação da CEDH aos Estados para dar substância ao disposto na norma convencional.

Também a favor da margem de apreciação dos Estados, a CEDH optou por dar liberdade a cada Estado para definir os limites da apreciação em segunda instância. O tema foi discutido em relação à possibilidade de recorrer a instâncias superiores por questões de fato, ou apenas em questões de direito, consoante se observa dos seguintes trechos dos julgamentos da $\mathrm{CEDH}$ :

2. [...] The Court reiterates, however, that under the wording of Article 2 of Protocol No. 7 the Contracting States retain the power to decide how the right to re-examine shall be exercised and may limit its extent. In a number of States, re-examination is thus restricted to questions of law [...].

The Court accordingly holds that the fact that the applicant was able to appeal on points of law against the judgment of 31 March 1998 satisfied the requirements of Article 2 of Protocol No. 7 to the Convention.

No julgamento do caso Krombach vs. França, a CEDH delimitou os outros aspectos do artigo $2^{\circ}$ do Protocolo 7, e reafirmou o que expresso na exposição de motivos, no sentido de que tal dispositivo não exige que a revisão pelo órgão de maior hierarquia seja completa. Em outras palavras, a competência do órgão revisor pode estar adstrita às questões de direito, afastando-se assim a possibilidade de reanálise de fatos, sem que tal restrição configure uma violação ao artigo $2^{\circ}$ do Protocolo 7 :

96. The Court reiterates that the Contracting Status dispose in principle of a wide margin of appreciation to determine how the right secured by Article 2 of Protocol No. 7 to the Convention is to be exercised. Thus, the review by a higher court of a conviction or sentence may concern both points of fact and points of law or be confined solely to points of law. 
Da análise do texto do artigo $2^{\circ}$ do Protocolo 7 , em conjunto com a respectiva exposição de motivos e com os precedentes firmados pela CEDH, é possível afirmar que a garantia do duplo grau de jurisdição possui contornos bem flexíveis. Há, efetivamente, uma zona de legalidade dentro da qual aos Estados é deferida a discricionariedade para regulamentarem tal garantia processual em atenção às peculiaridades de seu ordenamento jurídico.

Assim sendo, a forma como a CEDH desenhou os limites gerais do direito ao duplo grau de jurisdição possibilitou a existência simultânea de um nível mínimo de proteção de tal garantia processual e de uma efetiva pluralidade que poderá ser exercida pelo reconhecimento da margem de apreciação nacional.

\section{0 duplo grau de jurisdição na Corte Interamericana de Direitos Humanos}

Na América Latina, as garantias judiciais são vistas como o 'direito a ter direitos', ou mesmo como a 'fundação do sistema de proteção dos direitos humanos'” (QUIROGA, 2003, p. 267). Nessa quadra, a garantia ao duplo grau de jurisdição ("derecho de recurrir del fallo ante juez o tribunal superior") já foi diversas vezes afirmada pela Corte Interamericana como sendo uma garantia primordial, que visa assegurar o próprio direito de defesa. Ao contrário da Corte Europeia de Direitos Humanos, a CIDH é mais rígida e detalhista ao delinear o princípio do duplo grau de jurisdição, retirando dos Estados a possibilidade de dar conteúdo próprio aos conceitos. Na Convenção Americana, o duplo grau está previsto no artigo 8.2. h que assim dispõe:

8. 2. Toda pessoa acusada de um delito tem direito a que se presuma sua inocência, enquanto não for legalmente comprovada sua culpa. Durante o processo, toda pessoa tem direito, em plena igualdade, às seguintes garantias mínimas:

[...]

h) direito de recorrer da sentença a juiz ou tribunal superior.

O duplo grau está, portanto, delineado na Convenção Americana como o direito de recorrer de uma sentença, sendo que tal recurso pode estar dirigido tanto a outro juiz singular como também a um tribunal superior. Sua inserção na Convenção Americana foi inspirada no artigo 14 da Convenção Internacional de Direitos Civis e Políticos, e essa maior proteção teria sido conferida com o intuito de se "adequar as necessidades do Continente americano".

A Convenção não esclarece alguns pontos, como o significado de sentença - quando proferida por juiz singular - em contraposição ao conceito de acórdão - decisão emanada de um colegiado de juízes -; qual o alcance desse recurso; se abrange questões fáticas ou jurídicas; e se deve, necessariamente, haver um recurso em face da decisão condenatória proferida por um tribunal após reforma da sentença de absolvição.

Tais questões, que seriam posteriormente aclaradas mediante os julgados da CIDH, demonstram a importância da análise da jurisprudência como instrumento para a correta definição dos conceitos jurídicos presentes na Convenção Americana.

A construção do direito ao duplo grau de jurisdição pela jurisprudência interamericana é especialmente relevante quando se observa que tal direito insere-se no denominado "núcleo rígido" dos direitos protegidos pela Convenção (BURGOGUE-LARSEN; TORRES, 2011, p. 645), não podendo ser suspensos, mesmo em casos de emergência. Aliás, é justamente para evitar julgamentos por tribunais de exceção, bastante comuns em diferentes períodos da história latino-americana, que o princípio se torna mais relevante.

O preenchimento das lacunas interpretativas do artigo 8.2.h. da Convenção Americana foi sendo devidamente construído pela jurisprudência da CIDH. Entre os pontos discutidos pela CIDH, destacamse: o acesso real aos tribunais superiores; a necessidade de reexame integral da decisão de primeira instância, envolvendo questões de fato e de direito; a existência de jurisdição superior quando há decisão condenatória, mesmo que seja uma terceira instância; e a possibilidade do reexame ser realizado pelo 
mesmo tribunal, quando há foro privilegiado. No tocante ao primeiro ponto, real acesso aos tribunais superiores, dentre as premissas firmadas pelos julgamentos da Cortes, destaca-se a afirmação de que referido direito "não se satisfaz pela mera existência de um órgão superior que julgue e condene o culpado, mas também que este tenha e possa ter acesso".

Além do acesso ao tribunal superior, deve esse ter jurisdição e competência para revisar a sentença condenatória, ou seja, o tribunal superior deve ter a legitimidade para rever não apenas o direito aplicável à espécie como também reanalisar os fatos postos no processo. Em outras palavras, "o importante é que dito recurso garanta um exame integral da decisão recorrida". Nota-se aqui que a CIDH estende as obrigações dos Estados além do previsto pela CEDH.

O tema foi tratado no julgamento do caso Herrera Ulloa vs. Costa Rica, em que os representantes das vítimas sustentaram a violação ao artigo 8.2.h da Convenção exatamente porque o recurso disponível naquele país (recurso de cassação) não permitia a reavaliação e revaloração das provas. Embora na manifestação apresentada pela Comissão tenha sido afirmado que "a Convenção não exige que o Estado disponha de uma segunda instância - entendida esta como uma revisão plena do fato ditado pela instância a quo", a decisão da CIDH foi mais ampla, impondo aos Estados a obrigação de que seja previsto sempre uma revisão plena do que foi decidido pelo órgão judicial recorrido, tendo sido determinada a adequação do ordenamento jurídico doméstico (MERA, 2011, p. 44) consoante se observa do seguinte trecho da decisão:

167. En el presente caso, los recursos de casación presentados contra la sentencia condenatoria de 12 de noviembre de 1999 no satisficieron el requisito de ser un recurso amplio de manera tal que permitiera que el tribunal superior realizara un análisis o examen comprensivo e integral de todas las cuestiones debatidas y analizadas en el tribunal inferior. Esta situación conlleva a que los recursos de casación interpuestos por los señores Fernán Vargas Rohrmoser y Mauricio Herrera Ulloa, y por el defensor de éste último y apoderado especial del periódico 'La Nación', respectivamente (supra párr. 95. w), contra la sentencia condenatoria, no satisficieron los requisitos del artículo $8.2 \mathrm{~h}$. de la Convención Americana en cuanto no permitieron un examen integral sino limitado. (Grifo nosso).

É interessante observar que a CIDH não esclareceu, nessa oportunidade, o alcance do que seria um 'exame compreensivo e integral'. Contudo, a partir dos argumentos sustentados pelos requerentes, e considerando a condenação do Estado da Costa Rica, é possível concluir que o tribunal revisor deve ter competência para rejulgar não apenas o direito aplicável à espécie, como também os fatos discutidos.

Posteriormente, no julgamento do caso Mohamed vs. Argentina, a CIDH deixou expressa a necessidade de que o recurso alcance questões de fato e de direito, para que possa cumprir com a garantia do duplo grau de jurisdição, nos termos previstos na Convenção Americana:

100. Debe entenderse que, independientemente del régimen o sistema recursivo que adopten los Estados Partes y de la denominación que den al medio de impugnación de la sentencia condenatoria, para que éste sea eficaz debe constituir un medio adecuado para procurar la corrección de una condena errónea. Ello requiere que pueda analizar cuestio cuestiones fácticas, probatorias y jurídicas en que se basa la sentencia impugnada, puesto que en la actividad jurisdiccional existe una interdependencia entre las determinaciones fácticas y la aplicación del derecho, de forma tal que una errónea determinación de los hechos implica una errada o indebida aplicación del derecho. Consecuentemente, las causales de procedencia del recurso deben posibilitar un control amplio de los aspectos impugnados de la sentencia condenatória. (Grifo nosso).

Também nesse caso, a CIDH novamente ampliou o alcance da garantia estabelecida no artigo 8.2.h da Convenção Americana, para afirmar que o ordenamento jurídico doméstico deve prever um recurso integral contra a decisão condenatória. Em outras palavras, caso o indivíduo seja absolvido em primeira instância e condenado após recurso do órgão acusador, deve ser garantido um novo recurso irrestrito contra o acórdão condenatório: 
90. La Corte hace notar que este caso presenta la particularidad de que al imputado se le siguió un proceso penal de dos instancias, y fue condenado en segunda instancia por un tribunal que revocó la decisión absolutoria del juzgado de primera instancia. Para determinar si al señor Mohamed le asistía el derecho de recurrir del fallo ante juez o tribunal superior, corresponde determinar si la protección consagrada en el artículo 8.2.h de la Convención Americana permite una excepción, tal como alega Argentina, cuando el imputado haya sido declarado condenado por un tribunal que resuelva un recurso contra su absolución.

\section{[...]}

92. Teniendo en cuenta que las garantías judiciales buscan que quien esté incurso en un proceso no sea sometido a decisiones arbitrarias, la Corte interpreta que el derecho a recurrir del fallo no podría ser efectivo si no se garantiza respecto de todo aquél que es condenado, ya que la condena es la manifestación del ejercicio del poder punitivo del Estado. Resulta contrario al propósito de ese derecho específico que no sea garantizado frente a quien es condenado mediante una sentencia que revoca una decisión absolutoria. Interpretar lo contrario, implicaría dejar al condenado desprovisto de un recurso contra la condena. Se trata de una garantía del individuo frente al Estado y no solamente una guía que orienta el diseño de los sistemas de impugnación en los ordenamientos jurídicos de los Estados Partes de la Convención. (Grifo nosso).

Outra lacuna verificada no mesmo artigo da Convenção Americana que precisava ser preenchida pela $\mathrm{CIDH}$ refere-se à ausência do duplo grau quando a parte possua foro privilegiado e, portanto, seja julgada diretamente pelo tribunal de maior hierarquia do país. Essa situação ocorreu no Brasil, com os recentes julgamentos de agentes políticos. O tema foi objeto de denúncia por parte de advogados brasileiros no caso do mensalão frente à Comissão Interamericana de Direitos Humanos.

A iniciativa dos brasileiros foi fundamentada no precedente firmado pela $\mathrm{CIDH}$ no julgamento do caso Barreto Leiva vs. Venezuela. Nesse caso, a vítima havia sido condenada em seu país de origem contra crimes contra o patrimônio. Dentre outros vícios processuais sustentados, arguiu-se a ofensa ao direito ao duplo grau de jurisdição, pois o requerente havia sido julgado pela Suprema Corte de Justiça da Venezuela, em única instância, uma vez que um dos coautores era o Presidente daquele País.

Ao decidir especificamente sobre a ofensa à garantia ao duplo grau de jurisdição, a CIDH afirmou peremptoriamente que, apesar de ser possível a instituição de foros privilegiados, ainda assim "o Estado deve permitir que o indivíduo submetido à justiça conte com a possibilidade de recorrer da decisão condenatória", sendo aceitável que a revisão seja efetuada por outro órgão do mesmo tribunal.

Nesse contexto, a Venezuela foi condenada pela violação ao artigo 8.2.h da Convenção Americana, tendo sido pacificado o entendimento de que a garantia do duplo grau de jurisdição não admite qualquer espécie de margem de apreciação por país, diversamente do que ocorre na jurisdição europeia.

Tal entendimento foi reafirmado quando do julgamento do caso Liakat Ali Alibux vs. Suriname, sedimentando a jurisprudência no sentido de não excepcionar o julgamento pela mais alta corte do país de observar a garantia do duplo grau de jurisdição. Ademais, nesse julgamento, a CIDH fora instada a analisar a jurisprudência da $\mathrm{CEDH}$, que permite o julgamento em instância única pelo tribunal de maior hierarquia do país, tendo afirmado que, como a Convenção Americana não havia previsto as mesmas exceções contidas no Protocolo 7 da Convenção Europeia, não poderia a CIDH aplicar as exceções ali previstas. Nota-se que o próprio Supremo Tribunal Federal alterou seu regimento interno para transferir do Plenário para as Turmas a competência para o julgamento de crimes cometidos por agentes políticos. Garante-se, desse modo, não apenas a celeridade do processo, mas um maior respeito ao duplo grau de jurisdição, sem ofender ao princípio constitucional e convencional da ampla defesa. Ainda assim, considerando os limites do recurso cabível ao Plenário (embargos infringentes), permanece a violação ao artigo 8.2.h nos termos delineados pela CIDH.

Por fim, a exigência de duplo grau de jurisdição por autoridade judicial foi discutida pela Comissão Interamericana de Direitos Humanos no tocante a julgamentos administrativos. O processo, que gerou muita repercussão, discutia a possibilidade de um tribunal administrativo destitutir o prefeito de Bogotá, Gustavo Petro Urego, por irregularidades administrativas. Nesse caso, o prefeito de Bogotá foi destituído do 
cargo e recorreu à Comissão Interamericana alegando violação ao princípio da ampla defesa. Ao contrário dos casos anteriores, discutia-se os remédios legais para que o prefeito de Bogotá pudesse rediscutir em instância judicial a sua destituição por meio de processo administrativo, conduzido pela Procuradoria Geral da Nação. No direito colombiano, o direito disciplinar era exaurido nos fóruns administrativos e conduzido pela Procuradoria Geral da Nação. De acordo com a Comissão, a destituição de cargo público, sem possibilidade de revisão por tribunal judicial, significa também a violação ao princípio da ampla defesa. Ao final, a Colômbia aceitou reinstituir Gustavo Petro Urego no cargo deposto.

Da análise da jurisprudência da CIDH, é possível afirmar que a interpretação conferida ao artigo 8.2.h foi realizada de forma a conferir um caráter absoluto ao direito ao duplo grau de jurisdição. Resta, portanto, questionar se era realmente essencial a existência de exceção expressa no texto da Convenção Americana para que a CIDH estabelecesse uma jurisprudência mais 'fluida' desse direito, deferindo alguma margem de apreciação aos Estados, ou se tal posicionamento apenas reflete uma estrutura de tomada de decisão fundamentada no controle interpretativo mais restrito.

\section{A construção dos direitos humanos e o papel interpretativo das Cortes}

Após ter estabelecido o conceito do duplo grau de jurisdição na CEDH e na CIDH, foi possível perceber que tal direito fundamental é concebido de forma bastante diversa nas duas Cortes, suscitando o questionamento se existe um nível ideal de direitos humanos que deve ser impreterivelmente estabelecido em qualquer país do mundo, ou se realmente haveria a possibilidade de um maior pluralismo na internacionalização do direito.

No caso, enquanto a CEDH optou por estabelecer um nível mínimo de garantia, prevendo exceções expressas ao direito ao duplo grau de jurisdição e deferindo aos Estados-membros uma ampla margem de apreciação para a construção doméstica de tal garantia; a CIDH caminhou em sentido oposto, interpretando a Convenção Americana de forma a conferir um caráter absoluto à garantia do duplo grau, restando aos Estados praticamente nenhum espaço para a apreciação interna de referido direito.

Para que seja possível entender porque as duas principais Cortes de direitos humanos possuem jurisprudência tão díspares quanto ao referido direito, é essencial analisar o processo hermenêutico de tais Tribunais para verificar como os procedimentos e instrumentos utilizados impactam na construção dos direitos dentro de cada um desses sistemas de proteção.

Percebe-se, assim, que a utilização da margem de apreciação nacional como um recurso hermenêutico está inserindo dentro de um sistema de direitos humanos que possui o pluralismo como um de seus pilares fundamentais, o qual visa assegurar o equilíbrio entre as esferas doméstica e internacional, e não somente a submissão daquela a esta. Nesse contexto, embora seja possível determinar um núcleo essencial dos direitos humanos, esse deverá ser o menor possível, com vistas a preservar a diversidade no âmbito doméstico, que deve ser a esfera primária de proteção dos direitos humanos.

No âmbito europeu, a margem nacional de apreciação ocorre, sobretudo, quando há temas de maior sensibilidade, cuja decisão da CEDH não seria bem-vinda ou de baixa efetividade. Procura-se construir os elementos necessários para induzir uma interpretação comum e, com o ambiente favorável, reduzir a margem, de forma a construir gradualmente o consenso. A margem nacional de apreciação é assim importante instrumento para a efetividade das decisões da CEDH.

Isso seria possível mesmo dentro de um cenário de internacionalização, pois, de acordo com a doutrina da margem de apreciação, em relação a determinados direitos - de normatividade flexível -, existe uma zona de legalidade dentro da qual o Estado estaria livre para atuar. Assim, ao interpretar uma mesma norma internacional, diferentes autoridades nacionais, em diferentes Estados, poderiam gerar decisões diferentes, com níveis diferentes de proteção do direito, mas todas consideradas legais (SHANY, 2006, p. 910). 
Nesse ponto, percebe-se que a utilização da margem como instrumento hermenêutico propicia tanto uma deferência da Corte em relação ao ordenamento jurídico doméstico como também afeta a própria construção do direito dentro da Corte, cuja definição poderia ser mais fluida com o intuito de abarcar a diversidade observada dentro dos Estados (KRATOCHVÍL, 2011, p. 328).

É interessante ressaltar que a primeira vez que a $\mathrm{CIDH}$, em jurisdição contenciosa, fez menção ao termo margem de apreciação foi justamente na análise da violação ao artigo 8.2.h da Convenção, no julgamento do caso Herrera Ulhoa vs. Costa Rica, quando afirmou que "embora os Estados tenham uma margem de apreciação para regular o exercício desse recurso, não podem estabelecer restrições ou requisitos que infrinjam a própria essência do direito a recorrer da decisão". Em outras palavras, a ideia de margem nacional de apreciação foi citada para ser negada.

Ao delimitar o direito ao duplo grau de jurisdição, a CIDH impôs limites, cujo resultado prático é a impossibilidade de flexibilização da garantia do duplo grau de jurisdição. Em outras palavras, o direito foi construído de tal forma que não apenas é muito difícil um Estado conseguir efetivamente prever tal direito de forma diversa daquela determinada pela $\mathrm{CIDH}$, como também, na realidade, a maioria dos sistemas jurídicos acaba por violar o artigo 8.2.h da Convenção.

Conclui-se, portanto, que embora a CIDH tenha afirmado tal possibilidade em diversos dos precedentes citados, o fato é que as restrições impostas pela jurisprudência sobre a garantia ao duplo grau de jurisdição tornaram tal margem praticamente impossível de ser usufruída pelo ordenamento jurídico doméstico.

Vários argumentos são utilizados para justificar a ausência ou a impossibilidade de utilização da margem de apreciação nacional como um legítimo instrumento interpretativo pela CIDH, dentre os quais, destacam-se: menor experiência em relação à $\mathrm{CEDH}$; diferença dos direitos violados; ausência de um intenso pluralismo social, religioso e cultural na América Latina (SALDANHA; BRUM, 2015, p. 217; NUÑES POBLETE, 2012, p. 35).

As duas primeiras justificativas poderiam ser usadas para afastar a incidência da margem de apreciação em determinados casos em que a violação do direito não comportava qualquer grau de relativização. De fato, a margem de apreciação somente pode ser utilizada quando há efetivamente uma zona de legalidade para o exercício de determinado direito.

Por outro lado, é intuitivo aceitar que a CIDH teria se dedicado, inicialmente, ao julgamento das violações mais graves de direitos humanos, o que afastaria os requisitos indispensáveis para a utilização desse instrumento. Nesse contexto, é de se esperar que a utilização de tal método integrativo não tenha a capilaridade observada no âmbito europeu.

Entretanto, como já dito, a escolha do duplo grau de jurisdição como garantia a ser analisada no presente artigo não foi feita de forma aleatória, mas sim visando ultrapassar argumentos que envolvessem não apenas questões morais ou religiosas, mas também que possibilitassem a discussão acerca dos limites aceitáveis para a relativização de tal garantia. Logo, independentemente das demais violações a direitos humanos observados, a garantia processual do duplo grau de jurisdição poderia ser analisada em separado para se concluir pela aplicação da margem tão somente na referida garantia.

Quanto ao terceiro argumento, de que a América Latina teria uma maior homogeneidade cultural, o que tornaria desnecessária a utilização da margem de apreciação, é interessante observar que vários Estados membros seriam ou foram condenados por violação ao direito ao duplo grau de jurisdição, na forma como delineado pela jurisprudência da $\mathrm{CIDH}$, mas não o seriam se utilizado os padrões definidos pela CEDH. Tanto é assim que vários desses Estados suscitaram que seus ordenamentos jurídicos internos cumpriam o standard mínimo de tal garantia, conforme delineado no Protocolo 7 da Convenção Europeia.

Mesmo o argumento utilizado pela CIDH no sentido de que a Convenção Americana não previu as exceções ao duplo grau de jurisdição expressas no Protocolo 7 da Convenção Europeia não se sustenta diante da análise da jurisprudência da Corte, porque o artigo 8.2.h possui redação genérica, cujas lacunas 
foram sendo preenchidas pela jurisprudência. Assim, o duplo grau de jurisdição no Sistema Interamericano não é resultado de uma interpretação literal do texto da Convenção, mas foi sendo passo a passo construído pela $\mathrm{CIDH}$, a qual optou por conferir um caráter absoluto a referida garantia.

Como antes explanado, questões como o alcance material do recurso disponível e o próprio conceito de sentença - decisão proferida por juiz singular - em contraposição à necessidade de recurso contra acórdão, que não estavam claras e expressas na Convenção, foram resolvidas pela CIDH, o que culminou na inserção do elemento 'condenatório' ao texto convencional, ampliando sobremaneira o standard mínimo de tal direito. Assim, a garantia ao duplo grau de jurisdição passou a ser entendida e afirmada como sendo um direito a recurso integral contra qualquer decisão condenatória, seja tal decisão sentença, seja acórdão.

Assim, embora em alguns outros casos controversos seja possível afirmar a ausência dos requisitos necessários para a aplicação da teoria da margem de apreciação, no que se refere especificamente ao direito ao duplo grau de jurisdição, encontravam-se presentes as condições necessárias para se aplicar referido método hermenêutico, de modo a transferir para as esferas domésticas a possibilidade de delimitarem tal garantia dentro do escopo mais amplo assegurado pela Convenção. Dessa maneira, as restrições impostas pela $\mathrm{CIDH}$ com o intuito de evitar qualquer relativização do direito ao duplo grau poderiam ser efetivadas dentro dos ordenamentos jurídicos nacionais.

Enquanto a CEDH utiliza a margem de apreciação como método interpretativo com o intuito de equilibrar a harmonização do direito internacional e o pluralismo dos ordenamentos sócio-político-jurídicos de seus Estados signatários, a CIDH opta por um caminho oposto, tomando para si a competência para reconstruir o modelo de garantia do duplo grau, deixando praticamente nenhum espaço para a complementação dos Estados signatários, mesmo estando presentes todos os requisitos necessários para a incidência da margem de apreciação.

Talvez, então, para que seja possível entender a recalcitrância da CIDH em aplicar a margem de apreciação, seja necessário alterar o olhar e direcioná-lo não mais à Corte, mas sim aos Estados signatários, para se questionar se, de fato, o doméstico é o lugar onde as incertezas sobre a zona da legalidade do direito poderão ser resolvidas. Ademais, é interessante questionar qual seria o instrumento utilizado pela CIDH para conciliar essa centralização da competência interpretativa com a necessidade de promover uma internalização dos direitos previstos na Convenção Americana.

\section{As falhas institucionais dos Estados e a ausência de confiança}

A margem de apreciação é também transferência de poder, é o momento no qual o Tribunal internacional se afasta dos Estados e reconhece que o doméstico é o locus legítimo para a definição daquele direito, confiando que aquele Estado está mais capacitado para essa tarefa.

Observa-se desconfiança da CIDH em relação aos Estados-membros, quanto à sua capacidade de proteção dos direitos garantidos pela Convenção. Essa divergência parece estar ligada ao ambiente político que vigia quando do início de ambas as Cortes, pois, enquanto no âmbito europeu já existiam várias democracias consolidadas, na América Latina a maioria dos Estados vivenciavam um ambiente político de ditaduras militares e regimes autoritários (CONTRERAS, 2012, p. 29).

Assim, tanto o histórico de governos ditatoriais, que diuturnamente violavam uma extensa gama de direitos humanos, como a atual dificuldade em conciliar o desenvolvimento econômico e social, fornecem uma imagem de que tais países não teriam competência - aqui utilizado propositadamente em seu duplo sentido - para delimitar os direitos cujos contornos não estejam expressos na Convenção.

Para que a CIDH consiga aplicar a margem de apreciação de forma mais ampla, é indispensável essa transferência de poder e de responsabilidade ao Estado-membro. Mas, ao que tudo indica, a CIDH não acredita que o direito será melhor delimitado no âmbito doméstico. A observação feita de forma simples e direta pelo então Juiz da CIDH, Antônio Cançado Trindade, é esclarecedora no ponto: 


\begin{abstract}
Afortunadamente tal doutrina no há encontrado um desarrollo paralelo explícito bajo la Convencion americana sobre Derechos Humanos. [...] [c]ómo pretender aplicarlo en un sistema regional en que el Poder Judicial de tantos países sufre todo tipo de presiones e intimidaciones. Cómo pretender aplicarlo en un continente en que la función judicial, em tantos países sigue siendo 'compartida' por el fuero ordinario o común, y fueros militares especiales. Cómo pretender aplicarlo en ordenamientos jurídicos nacionales severamente cuestionados por su ineficiência em el combate a la impunidad. En nuestro sufrido continente - así como en la pan-Europa convulsionada de hoy - dificilmente encontraríamos la doctrina básica sobre la cual se há erigido en las últimas décadas la doctrina del 'margen de apreciación' de los Estados em cuanto a los modos de cumplimiento de sus obligaciones convencionales em materia de derechos humanos. Siendo así, no resta otro caminho sino el fortalecimento de los mecanismos internacionales de protección, complementarios de las instancias nacionales. (Grifo nosso). (NUÑES POBLETE, 2012, p. 12).
\end{abstract}

Assim, ao contrário do que ocorre no âmbito europeu, em que ao compartilhar com os Estadosmembros a responsabilidade, tanto na proteção dos direitos humanos como na interpretação da respectiva convenção, a CEDH estabelece um mecanismo de parceria que fortalece o Estado, a própria Corte e, consequentemente, todo o sistema de proteção aos direitos humanos; na esfera interamericana, o que se observa é uma descrença nas instituições e no ordenamento jurídico local, o que dificulta esse traslado de jurisdição, pavimentando o caminho inverso da centralização da intepretação da Convenção unicamente na CIDH.

A questão que se coloca é se, no momento atual, a CIDH não deveria passar a utilizar a margem nacional de apreciação, porque há menor fraqueza institucional dos tribunais latino-americanos e a democracia na maior parte dos Estados está consolidada. É possível confiar, dessa forma, com maior segurança, no nível de efetividade de diferentes cortes.

Assim, a justificativa primordial para a resistência da CIDH em utilizar a margem de apreciação nacional não estaria ligada à possibilidade de determinado direito ser modulado de acordo com os diversos sistemas jurídicos nacionais, mas sim com o suposto subdesenvolvimento político, jurídico e cultural dos Estados-membros.

Outro elemento visto com desconfiança pela CIDH é a possibilidade do uso do consenso entre os países latino-americanos como parâmetro de interpetação. Novamente, o histórico de conflitos estruturais em direitos humanos poderia resultar no estabelecimento de padrões muito inferiores, que até mesmo impediriam a proteção de determinados direitos. (DULITZKY, 2015, p. 75). Ainda assim, permanece a crítica no sentido de que simplesmente ignorar a existência de tais consensos pode resultar no próprio enfraquecimento do sistema, e não no seu fortalecimento.

Nesse contexto, a história política e cultura da América Latina seria uma justificativa inegável para que, diversamente da $\mathrm{CEDH}$, que delega aos Estados não apenas a margem para a conceituação de um direito, mas também a forma de prevenção de futuras violações, a CIDH centralize tanto a definição dos contornos dos direitos como também determine medidas específicas de compensação, satisfação, e até mesmo a reforma ou anulação das decisões judiciais ou legislativas.

Assim, diante das instabilidades e incertezas políticas, culturais e morais dos países latino-americanos, o Sistema Interamericano toma para si uma função compensatória da "ausência de observância do direito e de padrões democráticos no nível doméstico".

Diante desse cenário de desconfiança quanto às instituições domésticas, qual seria a estratégia da CIDH para harmonizar e garantir a proteção dos direitos humanos nos Estados signatários?

Como já ressaltado, a margem de apreciação fundamenta-se em relevante princípio da instituição das Cortes internacionais, qual seja, o princípio da subsidiariedade, na medida em que se acredita que o âmbito primordial de defesa dos direitos é exatamente o doméstico. Mas um dos pilares fundamentais para a efetividade do citado princípio é a confiança de que os Estados signatários também irão realizar seu papel no sistema de proteção dos direitos humanos. Na ausência desse pilar, desenvolveu-se a ideia de que a CIDH deve compensar as falhas institucionais presentes nos países signatários. 
A CIDH, ao desacreditar a esfera doméstica de proteção dos direitos humanos, acabou por reduzir a importância da subsidiariedade - não apenas no tocante à interpretação da Convenção Americana -, criando novos instrumentos para promover a harmonização dos direitos humanos na América Latina, dentre os quais, destaca-se o denominado controle de convencionalidade.

Do ponto de vista do direito internacional, examina-se o cumprimento do tratado. O Estado é avaliado como um todo, independente do órgão ou da norma que descumpre o compromisso internacional, podendo, inclusive, a própria Constituição ser considerada contrária às obrigações internacionais. Naturalmente, a norma de base para avaliação do desrespeito é a Convenção Interamericana de Direitos Humanos, tal como interpretada pela Corte Interamericana.

No entanto, do ponto de vista doméstico prevalece a norma mais recente ou a interpretação dos tribunais nacionais, em especial o Supremo Tribunal Federal. Os agentes internos, inclusive os juízes nacionais, devem seguir o direito brasileiro, contrário, ou não à interpretação da Corte Interamericana. É comum no direito estrangeiro os tribunais constitucionais divergirem de tribunais internacionais da melhor forma de proteção dos direitos humanos, o que constitui um diálogo entre cortes, mas sempre com a prevalência da corte nacional, exceto quando essa altera sua posição. Certos autores, contudo, acreditam que os juízes deveriam, nesse caso, desconsiderar a posição dos tribunais superiores brasileiros e seguir diretamente a interpretação da Corte Interamericana de Direitos Humanos, o que faz pouco sentido.

Essencialmente, o controle de convencionalidade prevê que todo e qualquer juiz nacional deve utilizar o texto da Convenção Americana, como interpretada pela $\mathrm{CIDH}$, como parâmetro de validade das normas domésticas. Nesse caso, eventual falha do Legislativo em compatibilizar as leis à Convenção Americana poderia ser diretamente resolvida pelo Judiciário local (MERA, 2011, p. 54-55). Assim, "a Corte Interamericana assumiu para si a competência para exercer um controle abstrato das normas nacionais e impôs aos juízes nacionais a obrigação de verificar ex officio a conformidade do direito doméstico com os tratados de direitos humanos interamericanos".

Utilizando-se do controle de constitucionalidade como paralelo, a Convenção Americana se transmudaria em uma ConstituiçãoAmericana e a CIDH seria uma espécie de Suprema Corte Interamericana.

Uma das características primordiais do controle de convencionalidade é o fato de que sua atuação não é nem subsidiária nem complementar. Pelo contrário, ao determinar que os juízes domésticos devam aplicar diretamente a Convenção - como interpretada pela CIDH -, tal sistemática alça não apenas a Convenção, mas especialmente a CIDH para o topo da ordem legal latino-americana (DULITZKY, 2015, p. 47).

Duas questões aqui devem ser esclarecidas. Em primeiro lugar, não se pretende retomar toda a clássica discussão acerca da hierarquia das normas internas e internacionais, plasmadas especialmente na dicotomia monismo/dualismo, mas tão somente observar a forma como a CIDH constrói e internaliza os direitos.

A segunda questão, diretamente relacionada à primeira, refere-se ao fato de que o direito que deve ser utilizado como parâmetro no controle de convencionalidade não é necessariamente o texto da Convenção Americana, mas sim a interpretação de tais direitos efetivada pela $\mathrm{CIDH}$, como bem ressaltado no primeiro julgamento em que tal doutrina foi expressamente citada, o caso Almonacid-Arellano vs. Chile:

In other words, the Judiciary must exercise a sort of 'conventionality control' between the domestic legal provisions which are applied to specific cases and the American Convention on Human Rights. To perform this task, the Judiciary has to take into account not only the treaty, but also the interpretation thereof made by the Inter-American Court, which is the ultimate interpreter of the American Convention.

A diferença pode, à primeira vista, parecer sutil, mas, como visto da análise da construção da garantia do duplo grau de jurisdição, a interpretação e o texto convencional não são necessariamente coincidentes. 
Tomando por base referida garantia, é possível que controle de convencionalidade - tendo por base tão somente o texto da Convenção Americana -, gerasse interpretações divergentes nos magistrados nacionais acerca do alcance dos conceitos de recurso e de sentença. Entretanto, ao se estabelecer a coisa interpretada como parâmetro, o âmbito de atuação dos magistrados é drasticamente reduzido.

Percebe-se, assim, que apesar de parecer um instrumento que possibilita uma maior interação entre os níveis doméstico e interamericano, o controle de convencionalidade é essencialmente unidirecional (DULITZKY, 2015, p. 48); um mecanismo de simples reverberação das decisões da CIDH e não de parceria, como deveria ser um recurso efetivamente harmonizador.

Isso porque o controle de convencionalidade é utilizado pela CIDH para impor sua autoridade final como intérprete da Convenção, de modo que não seja aceitável um controle de convencionalidade por juízes domésticos que utilize uma interpretação diferente daquela estabelecida pela CIDH (DULITZKY, 2015, p. 69).

Observa-se, novamente, estar subjacente o discurso de que "os tribunais domésticos são inábeis, incapazes, desprovidos de poder e de vontade para intervir", e então, ao invés de conferir uma margem de apreciação para que os Estados signatários construam seus direitos dentro de padrões mínimos, mesmo que por meio do controle de convencionalidade, a CIDH determina não apenas qual interpretação deve ser conferida à Convenção, mas também como tais normas devam ser integradas no ordenamento interno.

Desse modo, "a Corte está realizando uma construção absolutista das obrigações convencionais", tanto ao aceitar apenas uma forma de internalização do tratado como quando ignora que a própria Convenção Americana, em seu artigo $2^{\circ}$, requer que os direitos serão garantidos por um processo constitucional.

Ademais, ao lhe conferir a competência até mesmo para retirar os efeitos de leis domésticas que conflitam com a Convenção Americana, a CIDH reforça a ideia de que sua função se aproxima mais de uma Corte Constitucional do que de um Tribunal de Direitos Humanos.

Não se está aqui discutindo que o controle de convencionalidade pode funcionar como um importante instrumento de construção e consolidação da ordem jurídica interamericana, ou mesmo para a formação de um ius commune. O que se questiona é a forma como tal construção vem sendo realizada dentro da América Latina mediante uma crescente centralização do poder e das competências unicamente na CIDH, a qual impõe sua visão de direitos humanos.

Um dos perigos dessa estratégia de internacionalização top-down é que se torna mais complexo evitar uma atuação abusiva da Corte internacional, o que transformaria a "harmonização em uma unificação forçada". Mais do que isso, esse monopólio da jurisdição da CIDH impede a própria harmonização dos direitos, a qual não pode ocorrer de cima para baixo.

\section{Conclusão}

Uma das questões amplamente debatidas no contexto de proteção dos direitos humanos é como conciliar a internacionalização de tais direitos com a pluralidade sócio-cultural e religiosa dos diversos Estados-membros de cada uma das jurisdições dos tribunais de direitos humanos. Dentro desse amplo contexto, selecionou-se o direito ao duplo grau de jurisdição, uma garantia essencialmente instrumental, que possibilitaria uma análise mais neutra do processo hermenêutico da $\mathrm{CEDH}$ e da CIDH.

O estudo do processo de construção de tal garantia, em ambas as Cortes, demonstrou que na CEDH houve uma preocupação - desde a exposição de motivos da norma que previa tal direito até os julgamentos - em se garantir a aplicação da margem de apreciação como uma forma de assegurar a pluralidade, ou um pluralismo ordenado, como defendido por Delmas-Marty.

A autora afirma que, embora existam diversos processos de interação possíveis, "a margem de apreciação nacional é a chave para o pluralismo ordenado", na medida em que permite não apenas o 
movimento centrífugo da resistência nacional para a integração, como também a dinâmica centrípeta ao estabelecer limites dos princípios compartilhados, criando a dicotomia "soberania controlada" x "primazia europeia relativa".

De outro lado, foi possível perceber a recalcitrância da CIDH em utilizar da margem de apreciação nacional ou de outro instrumento para delegar maiores competências para a proteção de direitos humanos na esfera doméstica. Tal resistência é amplamente reconhecida na doutrina, não apenas em relação à garantia aqui analisada, mas como padrão hermenêutico da própria Corte.

Afastadas as justificativas formais para a utilização da margem de apreciação pela CIDH quanto à garantia ao duplo grau de jurisdição, e mudando o foco para os Estados signatários, observou-se que há uma desconfiança da Corte em relação ao padrão democrático e de direitos humanos estabelecido nos Estados signatários após décadas de ditadura militar, o que impede a CIDH de utilizar não apenas a margem de apreciação, mas também a leva a relegar a um plano secundário o próprio princípio da subsidiariedade.

Como alternativa, a CIDH propõe uma estratégia top-down de internalização dos tratados de direitos humanos, criando o denominado controle de convencionalidade, que a coloca como intérprete última e inquestionável das normas presentes na Convenção Americana de Direitos Humanos. A complexa dicotomia de movimento centrípeto e centrifugo presente no processo de integração europeu, que visa assegurar o equilíbrio entre o universal e o particular, entre o internacional e o doméstico, transforma-se assim em simples unificação.

O "direito comum" interamericano é, portanto, em grande parte, construído de forma absolutista e unilateral pela $\mathrm{CIDH}$, que agora passa a funcionar como uma espécie de Suprema Corte convencional da América Latina. Sem adentrar na discussão acerca da efetividade da Corte, ou mesmo dessa estratégia de internalização do direito, é importante questionar se realmente seria desejável a construção de um direito interamericano sem a intensa e efetiva participação dos países envolvidos, e se haveria espaço para um pluralismo nessa formatação estabelecida pela CIDH. A dúvida agora é se, face ao estado atual de democracia em diversos países da América Latina e com relação a casos que discutem temas, como direito ao aborto e violações individuais - e não massivas - de direitos humanos, seria o caso de passar a adotar a margem nacional de apreciação.

Por mais que seja possível concordar com as falhas democráticas e institucionais presentes na maioria dos países latino-americanos, observa-se uma acelerada democratização a indicar a necessidade de um maior envolvimento dos Estados-membros na formação e na proteção dos direitos humanos, inserindo assim o importante elemento da diversidade.

Atualmente, o que se observa é que a pretensão da $\mathrm{CIDH}$ de um direito internacional unificado confunde-se com a necessidade de uma imposição uniforme e inquestionável do direito da forma como interpretada pela Corte, não restando praticamente nenhum espaço para o pluralismo.

Mais interessante é perceber que, enquanto a ideia acerca da instituição de um Tribunal Constitucional na União Européia é alvo de intensas discussões, na América Latina, essa função autoatribuída pela $\mathrm{CIDH}$, mediante o desenvolvimento de um controle de convencionalidade, não encontra praticamente nenhuma resistência.

Talvez a doutrina latino-americana tenha "sucumbido demasiado rápido ao encanto do internacional" (NUÑES POBLETE, 2012, p. 40) e, portanto, sua velocidade de integração seja de fato mais acelerada do que aquela observada na Europa; ou, talvez, seja apenas a cultura dos países colonizados, acostumados a internalizar os usos e costumes estrangeiros como standards da moral, como uma forma de escapar de sua própria selvageria, como se assim lhes fosse assegurada uma passagem para o outro lado do mundo. 


\section{Referências}

BRAUCH, Jeffrey A. The margin of appreciation and the jurisprudence of the European Court of Human Rights: threat to the rule of law. Columbia Journal of European Law, Hanover, v. 11, n. 1, p. 113-150, 2004-2005.

BURGOGUE-LARSEN, Laurence; TORRES, Amaya Úbeda. The Inter-American Court of Human Rights: case law and commentary. Oxford: Oxford University Press, 2011.

CAROZZA, Paolo G. Subsidiarity as a Structural principle of International Human Rights Law. American Journal of International Law, Notre Dame, v. 97, p. 38-79, 2003.

CONTRERAS, Pablo. National Discretion and International Deference in the Restriction of Human Rights: A Comparison between the Jurisprudence of the European and the Inter-American Court of Human Rights. NW. J. Int. Hum. Rights., Chicago, v. 11, n. 1, p. 28-82, 2012.

DELMAS-MARTY, Mireille. Towards a truly common law: Europe as a laboratory for legal pluralism. Cambridge: Cambridge University Press, 2002.

DELMAS-MARTY, Mireille. Ordering pluralism: a conceptual framework for undestanding the transnational legal world. Oxford: Hart Publishing, 2009.

DIAZ, Alvaro Paúl. La Corte Interamericana in vitro: comentários sobre su proceso de toma de decisiones a proposito del caso Artavia. Derecho Pùblico Iberoamericano, Santiago de Chile, n. 2, p. 303-345, abr. 2013.

DULITZKY, Ariel. An inter-american constitutional court? The invention of the conventionality control by the Inter-American Court of Human Rights. Texas International Law Journal, Texas, v. 50, n. 1, p. 4593, 2015.

GAROUPA, Nuno; MALDONADO, Maria A. The judiciary in political transitions: the critical role of U.S. constitutionalism in Latin America. Cardozo J. Int, \& Compl.. L., Texas, v. 19, p. 593-644, 2011.

KRATOCHVÍL, Jan. The Inflation of the Margin of Appreciation by European Court of Human Rights. Netherlands Quarterly of Human Rights, Utrecht, v. 29/3, p. 324-357, 2011.

MERA, M. E. G. Inter-american judicial constitutionalism. Costa Rica: IIDH, 2011.

NEUMAN, Gerald L. Import, Export, and Regional Consent in the Inter-American Court of Human Rights. The European Journal of International Law/EJIL, Firenze, v. 19, n. 1, p. 101-123, 2008.

NUÑEZ POBLETE, Manuel. Sobre la doctrina del margen de apreciación nacional: la experiência latino-americana confrontada y el thelos constitucional de una técnica de adjudicación del derecho internacional de los derechos humanos. Ciudad de México: Universidad Nacional Autónoma de México, 2012. Disponível em: <https://archivos.juridicas.unam.mx/www/bjv/libros/7/3160/6.pdf> Acesso em: 12 fev. 2017.

QUIROGA, Cecilia Medina. La convencion americana: teoria y jurisprudência. Vida, integridad personal, libertad personal, debido processo y recurso judicial. Costa Rica: University of Chile, Faculty of Law, Centro de Derechos Humanos, 2003.

SALDANHA, Jânia Maria Lopes; BRUM, Márcio Morais. A margem nacional de apreciação e sua (in)aplicação pela Corte Interamericana de Direitos Humanos em matéria de anistia: uma figura hermenêutica a serviço do pluralismo ordenado? In: Anuario Mexicano de Derecho Internacional. Cidade do México: Instituto de Investigaciones Jurídicas, 2015. v. XV. p. 195-238.

SHANY, Yuval. Toward a general margin of appreciation doctrine in international law?. The European Journal of International Law-EJIL, Firenze, v. 16, n.5, p. 907-940, 2006.

SINGH, Mallika. A, B, C v. Ireland and the Doctrine of Margin of Appreciation. dez. 2011. Disponível em: <http://papers.ssrn.com/sol3/cf_dev/AbsByAuth.cfm?per_id=1732835>. Acesso em: 23 fev. 2017. 
SPIELMAN, Dean. Allowing the right margin the European Court of Human Rights and the National Margin of Appreciation Doctrine: waiver or subsidiarity of european review? CELS Working Paper Series, Cambridge, v. 14, p. 381-418, fev. 2012.

Recebido em: 23/03/2016

Aprovado em: 08/11/2017 